\title{
O Sistema Único de Assistência Social e o trabalho de assistência Social no PAIF: análise dos 13 anos de implantação em âmbito nacional e no município de Teresina-PI
}

\section{The Unique Social Assistance System and social work with families in PAIF: analysis of the 13 years of implementation nationwide and in the city of Teresina-PI}

\author{
Juliana Lima de Carvalho* \\ Solange Maria Teixeira*
}

\begin{abstract}
Resumo: A assistência social brasileira percorreu longo caminho até se tornar política pública e garantidora de direitos sociais. Como política de Estado, passou por um momento de hipertrofia, "fase ouro", e, posteriormente, iniciou nova fase, em 2016. Analisar e verificar as tendências do Sistema Único de Assistência Social e do Serviço de Atenção e Proteção Integral às Famílias na proteção social básica, nas duas séries históricas, no cenário nacional e com recorte específico no município de Teresina-PI, é o objetivo do presente artigo. A pesquisa é teórica, de base bibliográfica, documental e com dados quantitativos do Censo SUAS e do Relatório Mensal de Atividades (RMA) de Teresina, com metodologia qualiquantitativa e análises com base na perspectiva teórico-metodológica marxista. Conclui que os CRAS e o PAIF assumem tendências cartoriais, atendimentos individualizantes, baixa capacidade para acompanhamentos e centralidade nas situações de retorno à condição de beneficiário, dada pela imposição do cumprimento das condicionalidades.
\end{abstract}

Palavras-chave: Política Social. Assistência Social. Trabalho Social com Famílias.

Abstract: Brazilian social assistance has come a long way to become a public policy and guarantor of social rights. As a state policy, it went through a time of hypertrophy, the "golden stage" and, later, started a new stage in 2016.

\footnotetext{
* Mestre em Políticas Públicas pela Universidade Federal do Piauí. Graduada em Serviço Social pela Faculdade Adelmar Rosado. E-mail: juliana.lima28@hotmail.com.

** Pós-Doutora em Serviço Social pela PUC-SP e Doutora em Políticas Públicas pela Universidade Federal do Maranhão. Docente da Universidade Federal do Piauí, da Graduação em Serviço Social e da Pós-Graduação em Políticas Públicas. É bolsista de Produtividade do CNPQ. E-mail: solangemteixeira@hotmail.com.
} 
Analyze and verify the trends of the Unified Social Assistance System and the Care Service and Integral Protection to Families in basic social protection, in the two historical series, in the national scenario and with specific focus in the municipality of Teresina-PI, constituted the objective of this article. It is a theoretical research, based on bibliographical, documental, and quantitative data from the SUAS Census and from the Monthly Activity Report (RMA) of Teresina, with qualitative-quantitative methodology and analyzes based on the Marxist theoretical-methodological perspective. It was concluded that the CRAS and PAIF assume notary tendencies, individualizing services, low capacity for monitoring and centrality in situations of return to the condition of beneficiary, given by the imposition of compliance with conditionalities.

Keywords: Social Policy. Social assistance. Social Work with Families.

Recebido em 23/10/2020. Aceito em 20/07/2021

\section{Introdução}

A assistência social brasileira tem sua historicidade marcada pelo assistencialismo ${ }^{1}$ e clientelismo², mesmo quando da intervenção do Estado, nos anos de 1930 a 1980 . As tentativas de firmá-la como uma política pública começam nos movimentos sociais e nas ações coletivas no período da Constituinte, sendo absorvida pela Constituição Federal (CF) (BRASIL, 1988). A Lei Orgânica da Assistência Social (LOAS), mesmo aprovada em 1993, não conseguiu adesão governamental na década de 1990 para implementá-la, mantendo as ações da assistência social de forma pontual e intermediadas pelas instituições não governamentais, com marcas do assistencialismo que se somam ao voluntariado. Esse cenário muda apenas nos anos 2000, com a ascensão de Luís Inácio Lula da Silva à Presidência, pelo Partido dos Trabalhadores (PT), partido de esquerda no Brasil, momento em que houve a aprovação da Política Nacional de Assistência Social (PNAS) (BRASIL, 2004a) e a criação do Sistema Único da Assistência Social (SUAS) (BRASIL, 2005).

A implementação do Serviço de Proteção e Atendimento Integral à Família (PAIF), como serviço continuado de atenção às famílias, materializado pelo trabalho social com famílias, encontra-se atrelada à conjuntura de institucionalização e consolidação do SUAS. Trata-se de um serviço existente na rede de proteção socioassistencial, ofertado em todo o território nacional, por via municipal, mais próximo da realidade das famílias. Esse e outros serviços da proteção social básica e especial vêm dando a base de concretização da assistência social como política

\footnotetext{
${ }^{1}$ Iamamoto (2013) entende o assistencialismo como a forma de oferta de um serviço por meio de uma doação, favor, boa vontade ou interesse de alguém, e não como um direito, portanto, uma prática de dominação que produz a manipulação. Pelo valor da "gratidão", os assistidos se vinculam ao titular das ações de caráter assistencialista. Trata-se de uma prática que estimula a subserviência e a troca de favores.

${ }^{2}$ Fiuza e Costa (2015) dizem que o clientelismo está ligado diretamente à estrutura do poder político, a qual foi fundada e sustentada pela dominação tradicional. Contudo, suas expressões mais visíveis se manifestam nas ações junto aos mais pobres, baseadas nas "ajudas" materiais e favores, em que a população beneficiada acaba naturalizando essa relação, passando a considerá-la como a forma mais adequada para o atendimento de suas necessidades, e não sob a lógica do direito de cidadania.
} 
pública pautada nos direitos sociais, de base não contributiva, afiançando proteções sociais, especialmente as que visam garantir a convivência familiar e comunitária.

Conforme a Tipificação Nacional de Serviços Socioassistenciais (BRASIL, 2009a), o PAIF consiste no Trabalho Social com Famílias (TSF), de caráter continuado, com a finalidade de fortalecer a função protetiva delas, prevenir a ruptura de seus vínculos, promover o acesso e o usufruto de direitos e contribuir para a melhoria de sua qualidade de vida. Também prevê o desenvolvimento de potencialidades e aquisições das famílias e o fortalecimento de vínculos familiares e comunitários, por meio de ações de caráter preventivo, protetivo e proativo. Assim, o TSF é exclusivo dos Centros de Referência da Assistência Social (CRAS) e dos Centros de Referência Especializado da Assistência Social (CREAS), considerados, respectivamente, como portas de entrada das famílias aos serviços socioassistenciais ofertados nas proteções sociais básica e especial.

Tanto o SUAS quanto o PAIF, nas suas institucionalizações e nos seus desenvolvimentos, passaram por dois grandes momentos na realidade brasileira: o primeiro, de 2005 a 2015, de crescimento da normatização, das estruturas operacionais e dos serviços; e o segundo, que se iniciou em 2016, com o novo redirecionamento das políticas sociais, posto pela Emenda Constitucional ${ }^{\circ}$ 95 (BRASIL, 2016b). Assim, nasce a seguinte problematização: o que os dados nos revelam sobre os 13 primeiros anos de implementação do SUAS e do PAIF no cenário nacional e no município de Teresina-PI? A resposta a essa questão constitui-se o objetivo do artigo e o que nos remete a uma análise dessas duas séries históricas.

A pesquisa que deu origem ao artigo foi do tipo teórica e agregou três dimensões de análise, inter-relacionadas: a bibliográfica; a documental, com base na legislação; e a empírica, ancorada nos dados secundários fornecidos pelo Censo SUAS e pelo Relatório Mensal de Atividades (RMA) do município de Teresina-PI, a partir dos quais se busca fazer inferência sobre a implementação do SUAS, com destaque para o PAIF, seu desenvolvimento, sua consolidação e o apoio efetivo que concede às famílias em situação de vulnerabilidade social, destacando o município de TeresinaPI, pela qualidade da gestão local (gestão plena), pelo porte do município (grande porte) e pela localização (região Nordeste).

A metodologia utilizada foi a qualiquantitativa, pois as referências foram escolhidas de modo intencional, e os documentos analisados à luz de técnicas qualitativas, tais como portarias, decretos, leis, notas técnicas, plano decenal da assistência social, cadernos do SUAS, dentre outros documentos. Utiliza-se técnicas de análises quantitativas, como porcentagens e outras métricas com base em dados secundários dos Censos Suas dos anos referenciados neste estudo. Os dados dos relatórios de atendimento mensal foram retirados diretamente do site oficial da vigilância socioassistencial, sendo agregados e comparados, o que permitiu responder ao problema de pesquisa e aos objetivos propostos.

Com os dados estatísticos agregados, separados e comparados, obteve-se as prevalências e as regularidades, como a quantidade de famílias cadastradas no CadÚnico, famílias beneficiárias do Programa Bolsa Família (PBF), total de famílias inseridas no acompanhamento do PAIF/ano, total de atendimentos individualizados realizados, total de famílias participando regularmente de grupos no âmbito do PAIF, total de atendimentos coletivos do PAIF, realizados pelos 19 CRAS do município de Teresina. Esses dados para o método marxista são apenas a face imediata da realidade, as singularidades que mediante mediações e relações com a totalidade social, como o contexto histórico, conjuntural e estrutural do capitalismo brasileiro, processos de restaurações e alterações na lógica e planos governamentais, as contradições do contexto em que a Política de Assistência Social foi criada, implementada, desenvolvida e posteriormente, com mudanças que 
os números são expressões, relacionados a categoria do familismo, do trabalho social com famílias, direitos sociais, dentre outras, que permitiu chegar as conclusões apontadas neste estudo..

O método histórico-dialético permite analisar a realidade na relação singularidade, particularidade e totalidade. A totalidade não é a soma de partes e de números, mais um todo dinâmico, processual e com contradições, em que as singularidades estão inseridas e são explicadas, cujas ligações são postas pelas mediações determinantes. As análises dos resultados de uma política ou serviço específico, nessa perspectiva, não foge à análise que desvenda suas tendências.

Para atender ao objetivo proposto, os resultados da pesquisa foram divididos em dois grandes momentos: o dos primeiros dez anos de implementação do SUAS; e o que se inicia em 2016, com o Governo de Michel Temer, dando destaque, em ambas as séries históricas, ao PAIF no cenário nacional e no município de Teresina, concluindo sobre as tendências apontadas pelos dois momentos.

\section{Os primeiros dez anos do SUAS e do PAIF (2005-2015): contextualização em âmbito nacional}

A Política de Assistência Social está inserida no campo da seguridade social desde a promulgação da Carta Constitucional de 1988, que a reconhece como política pública de direito social, que deve ser assegurada pelo Estado. No entanto, esse avanço consideravelmente importante não foi o suficiente para dar base de atuação e sustentação à assistência social como política pública de caráter universal (ainda que no grupo focalizado dos que dela necessitam); isso porque a conjuntura política e econômica que o país vivenciava, pós-CF 88, com a adoção do ideário neoliberal nos anos de 1990, levou ao reforço do assistencialismo e do primeiro-damismo, descontinuidades que não favoreceram, de imediato, a concretização da assistência social como política pública.

Mesmo com a aprovação da LOAS, em 1993, ela se tornou "lei morta", ou seja, não foi implementada nos governos subsequentes. Contudo, somente com o afrouxamento do ideário neoliberal e a adoção de política de combate à pobreza, nos governos do PT (2003 a 2015), abriu-se um cenário em que os movimentos coletivos, em prol da assistência social, souberam se apropriar, vocalizar as demandas, influenciar nos espaços deliberativos, como as conferências e os conselhos. Aliada à nova estrutura ministerial para a assistência social e à política governamental, criaram-se espaços e diálogos que levaram à aprovação da PNAS (BRASIL, 2004a) e da NOB/ SUAS (BRASIL, 2005), pontapé inicial para implantação das estruturas estatais (CRAS e CREAS) e implementação dos serviços socioassistenciais, tipificados e uniformizados em 2009.

A implantação do SUAS reflete na responsabilização do Estado, mediante pacto federativo, em assumir a assistência social como política pública. Tem como princípios estruturantes a territorialidade e a matricialidade sociofamiliar. A partir dessas matrizes, são criados serviços, dentre eles o PAIF, que materializam a atenção pública às famílias em situação de vulnerabilidade e a indivíduos excluídos do acesso a direitos, nos seus territórios de vivências.

As normativas, embora se apresentem nessa conjuntura como avanços fundamentais para a consolidação da assistência social como uma política pública estatal, possuem elementos de manutenções, permanências, e até conservadores, como é o exemplo do "trabalho social com famílias", elaborado pela Política Nacional de Assistência Social, que reproduz as expectativas sociais sobre as funções familiares, naturalizando-as. Para melhor visualização do arcabouço jurídico-normativo de consolidação do SUAS, foi elaborado o quadro síntese, a seguir, com algumas das principais normatizações e os elementos que apontam avanços e/ou modernizações, 
manutenções e/ou conservadorismos que irão conduzir à materialização do PAIF, fazendo-se presentes na atualidade.

\section{Quadro 1 - Quadro síntese de normativas de 10 anos do SUAS e a presença de elementos de modernização e manutenções}

\begin{tabular}{|c|c|c|}
\hline $\begin{array}{l}\text { ARCABOUÇO } \\
\text { NORMATIVO }\end{array}$ & AVANÇOS/MODERNIZAÇÕES & MANUTENÇÕES/CONSERVADORISMOS \\
\hline $\begin{array}{l}\text { Resolução } n^{\circ} 45 \\
\text { de } 15 \text { de outubro } \\
\text { de } 2004 \text {. (BRASIL, } \\
\text { 2004a). }\end{array}$ & $\begin{array}{l}\text { Aprovação da Política Nacional da } \\
\text { Assistência Social (PNAS), que reúne } \\
\text { princípios, diretrizes, objetivos e ações } \\
\text { da assistência social, organizados por } \\
\text { níveis de complexidade, Proteção } \\
\text { Social Básica e a de Alta Complexidade. } \\
\end{array}$ & $\begin{array}{l}\text { Centralidade na família. Reconhece as } \\
\text { diversas configurações de formação de grupos } \\
\text { familiares. Porém, ainda reforça funções } \\
\text { tradicionais (guarda, socialização, educação, } \\
\text { sobrevivência) de responsabilização das } \\
\text { famílias, especialmente as mais pobres. }\end{array}$ \\
\hline $\begin{array}{l}\text { Portaria MDS } \\
n^{\circ} 080 / 2004 . \\
\text { (BRASIL, 2004c). }\end{array}$ & $\begin{array}{l}\text { Garantiu mais agilidade aos municípios } \\
\text { contemplados com o financiamento } \\
\text { dos serviços de ação continuada, foi } \\
\text { também necessário implantar um } \\
\text { Sistema Nacional de Informação } \\
\text { do SUAS e o desenvolvimento do } \\
\text { INFOSUAS. }\end{array}$ & $\begin{array}{l}\text { Modernização da política com sistema } \\
\text { de monitoramento e avaliação, agilidade } \\
\text { no repasse de recursos. Mas manteve a } \\
\text { desigualdade nas condições da oferta dos } \\
\text { serviços entre os municípios. }\end{array}$ \\
\hline $\begin{array}{l}\text { NOB/SUAS } \\
\text { Resolução no } 130, \\
\text { de } 15 \text { de junho } \\
\text { de 2005. (BRASIL, } \\
\text { 2005). }\end{array}$ & $\begin{array}{l}\text { Base de instituição do Sistema } \\
\text { Único da Assistência social, garante } \\
\text { a operacionalização da oferta dos } \\
\text { serviços e dá início ao processo de } \\
\text { adesão dos municípios brasileiros ao } \\
\text { novo modelo de gestão da assistência } \\
\text { social. }\end{array}$ & $\begin{array}{l}\text { Inova ao criar o sistema descentralizado e } \\
\text { com participação popular, definir formas } \\
\text { de gestões, responsabilidades dos entes } \\
\text { federados, financiamento. Mas ainda não criou } \\
\text { condições para a universalização no grupo } \\
\text { focalizado no acesso aos serviços e benefícios } \\
\text { que avançam com grande seletividade no } \\
\text { grupo-alvo. }\end{array}$ \\
\hline $\begin{array}{l}\text { NOB-RH/SUAS - } \\
\text { Resolução CNAS } \\
n^{\circ} 269 \text {, de } 13 \text { de } \\
\text { dezembro de } \\
\text { 2006. (BRASIL, } \\
\text { 2006). }\end{array}$ & $\begin{array}{l}\text { Estabelece diretrizes e princípios } \\
\text { que devem orientar os gestores das } \\
\text { três esferas de governo nas questões } \\
\text { relativas à gestão do trabalho e à } \\
\text { Educação Permanente no SUAS, ao } \\
\text { estabelecer a concepção de equipes de } \\
\text { referência, dentre outras. }\end{array}$ & $\begin{array}{l}\text { Reforça o Estado provedor de serviços } \\
\text { socioassistenciais e o trabalho profissional } \\
\text { estável e concursado; no entanto, não impediu } \\
\text { o avanço da terceirização do trabalho, dos } \\
\text { contratos temporários, a desvalorização } \\
\text { salarial e vínculos instáveis de trabalho. }\end{array}$ \\
\hline \begin{tabular}{|l} 
Tipificação \\
Nacional \\
de Serviços \\
Socioassistenciais, \\
Resolução \\
do Conselho \\
Nacional de \\
Assistência social \\
no 109, de 11 de \\
dezembro de \\
2009. (BRASIL, \\
2009a). \\
\end{tabular} & $\begin{array}{l}\text { Define uma matriz padronizada } \\
\text { nacionalmente para os serviços } \\
\text { socioassistenciais, estabelecendo as } \\
\text { correspondentes nomenclaturas, } \\
\text { destinatários, objetivos, provisões, } \\
\text { aquisições, condições e formas de } \\
\text { acesso, equipamentos utilizados, } \\
\text { período de funcionamento, } \\
\text { abrangência, articulação em rede, } \\
\text { impacto social esperado. }\end{array}$ & $\begin{array}{l}\text { Importante avanço na padronização dos } \\
\text { serviços e na explicitação dos seus objetivos } \\
\text { e destinatários; porém, não significou } \\
\text { obrigatoriedade da oferta estatal dos serviços. }\end{array}$ \\
\hline
\end{tabular}


conclusão

\begin{tabular}{|c|c|c|}
\hline $\begin{array}{l}\text { ARCABOUÇO } \\
\text { NORMATIVO } \\
\end{array}$ & AVANÇOS/MODERNIZAÇÕES & MANUTENÇÕES/CONSERVADORISMOS \\
\hline $\begin{array}{l}\text { Resolução CIT } \\
n^{\circ} 7, \text { de } 10 \text { de } \\
\text { setembro de } \\
\text { 2009. (BRASIL, } \\
\text { 2009b). }\end{array}$ & $\begin{array}{l}\text { Protocolo de Gestão Integrada de } \\
\text { Serviços, Benefícios e Transferências } \\
\text { de Renda no âmbito do Sistema Único } \\
\text { de Assistência Social (SUAS). }\end{array}$ & $\begin{array}{l}\text { Relevante para a articulação entre os } \\
\text { serviços e benefícios, com a priorização dos } \\
\text { beneficiários no atendimento dos serviços } \\
\text { e sua complementariedade. No entanto, } \\
\text { vem funcionando como um elemento } \\
\text { de seletividade na escolha dos usuários } \\
\text { dos serviços, limitando seu potencial de } \\
\text { prevenção. }\end{array}$ \\
\hline $\begin{array}{l}\text { Lei } \mathrm{n}^{\circ} \\
12.435 / 2011 . \\
\text { (BRASIL, 2011). }\end{array}$ & $\begin{array}{l}\text { Reformula a LOAS a partir dos } \\
\text { avanços do SUAS e da PNAS (2004), } \\
\text { que passam a fazer parte do escopo } \\
\text { da Lei Orgânica da Assistência Social. } \\
\text { Entre as providências, fica autorizado } \\
\text { o pagamento de pessoal das equipes } \\
\text { de referência, seja na proteção social } \\
\text { básica, ou na proteção social especial. }\end{array}$ & $\begin{array}{l}\text { Moderniza a LOAS, incluindo as inovações } \\
\text { que a assistência social sofreu nos anos } 2000 \text {. } \\
\text { Rompe com entraves no crescimento da } \\
\text { contratação da força de trabalho, criando } \\
\text { condições para sua contratação com o } \\
\text { cofinanciamento federal. Porém, não barrou a } \\
\text { sua precarização nas formas de contratação. }\end{array}$ \\
\hline $\begin{array}{l}\text { NOB/SUAS - } \\
\text { Resolução CNAS } \\
\mathrm{n}^{\circ} 33 \text {, de } 12 \text { de } \\
\text { dezembro de } \\
\text { 2012. (BRASIL, } \\
\text { 2012b) }\end{array}$ & $\begin{array}{l}\text { Aprova a Norma Operacional Básica do } \\
\text { Sistema Único de Assistência Social, } \\
\text { reforça a organização e estruturação } \\
\text { da Gestão do Trabalho no SUAS, } \\
\text { evidenciando-a como área essencial à } \\
\text { efetiva profissionalização do Sistema, } \\
\text { estabelecendo as responsabilidades } \\
\text { dos entes federados, entre elas a de } \\
\text { assegurar recursos financeiros para seu } \\
\text { cumprimento. }\end{array}$ & $\begin{array}{l}\text { Maior responsabilização dos quadros técnicos } \\
\text { (diga-se dos trabalhadores do SUAS) sobre } \\
\text { os resultados a serem alcançados com a } \\
\text { Política de Assistência Social, exige que o } \\
\text { profissional apresente um perfil que dê conta } \\
\text { da grande demanda, sem, contudo, assegurar- } \\
\text { lhe condições que possam atender às reais } \\
\text { demandas da família (BRAGA, 2018, p. 168). }\end{array}$ \\
\hline $\begin{array}{l}\text { Orientações } \\
\text { Técnicas sobre o } \\
\text { PAIF - volume } 1 \\
\text { (BRASIL, 2012a). }\end{array}$ & $\begin{array}{l}\text { Dispõe de orientações técnicas sobre } \\
\text { o Serviço de Proteção e atendimento } \\
\text { Integral à família (PAIF), segundo } \\
\text { a Tipificação Nacional dos Serviços } \\
\text { Socioassistenciais. }\end{array}$ & $\begin{array}{l}\text { Ênfase na centralidade da família e na } \\
\text { matricialidade sociofamiliar, mas insuficiente } \\
\text { para superar a perspectiva familista da } \\
\text { proteção social. }\end{array}$ \\
\hline $\begin{array}{l}\text { Orientações } \\
\text { Técnicas sobre o } \\
\text { PAIF - volume } 2 \\
\text { (BRASIL, 2012c). }\end{array}$ & $\begin{array}{l}\text { Dispõe sobre orientações do Trabalho } \\
\text { Social com Famílias no PAIF. }\end{array}$ & $\begin{array}{l}\text { Inova ao incluir metodologias participativas } \\
\text { de trabalho com famílias, mas não altera os } \\
\text { fins do trabalho, que é fortalecer as funções } \\
\text { protetivas da família. }\end{array}$ \\
\hline
\end{tabular}

Fonte: Elaborado pelas autoras com base nos documentos oficiais do MDS.

Foi esse arcabouço jurídico institucional que sustentou a implantação do SUAS no Brasil, transformando-se num novo modelo de gestão público, compartilhado e financiado entre os entes federados. Mesmo diante de avanços importantes quanto às normatizações e à efetivação da Política de Assistência, ainda perpassam manutenções e conservadorismos. Uma das que se fazem mais presentes é o familismo, em que a intervenção do Estado na família ocorre quando essa já não possui mais nenhum meio de prover sua proteção e a de seus membros.

Contudo, cabe ressaltar que a implementação do SUAS, em seus primeiros 10 anos, relaciona-se com as agendas estratégicas do Governo. Um exemplo é o Programa Fome Zero, lançado em 2003; dentre as estratégias, encontra-se a unificação dos programas de transferência de renda, 
que eram fragmentados e de baixa cobertura. Para a superação desse quadro, a iniciativa foi a criação do PBF, Medida Provisória no 132 (BRASIL, 2003b), programa de transferência de renda dirigido a famílias extremamente pobres.

Após 2005, as ações da assistência social ganharam nova configuração, principalmente no que se refere ao financiamento dos recursos, assumindo um modelo que passou a ser descentralizado, planejado e continuado. o crescimento desses investimentos foi fundamental para a implementação dos CRAS em todos os municípios. Essa indução do Governo Federal rumo à descentralização pode ser verificada pelo crescimento do orçamento da assistência social, de 2002 a 2012, cujos valores investidos pela União na Assistência Social apresentaram aumento considerável, como representa o gráfico 1, a seguir, conforme dados do Sistema de Informações sobre Orçamento Público Federal. Como se pode ver, o total executado passou de $\mathrm{R} \$ 23,8$ bilhões, em 2005, para R $\$ 60$ bilhões, em 2012, correspondendo a um crescimento real. Além disso, durante toda a série histórica, registrou-se crescimento anual positivo e reajuste nominal.

\section{Gráfico 1 - Recursos transferidos do orçamento da União para o financiamento da assistência social nos primeiros 10 anos de implantação do SUAS - Brasil (2005-2015)}

80

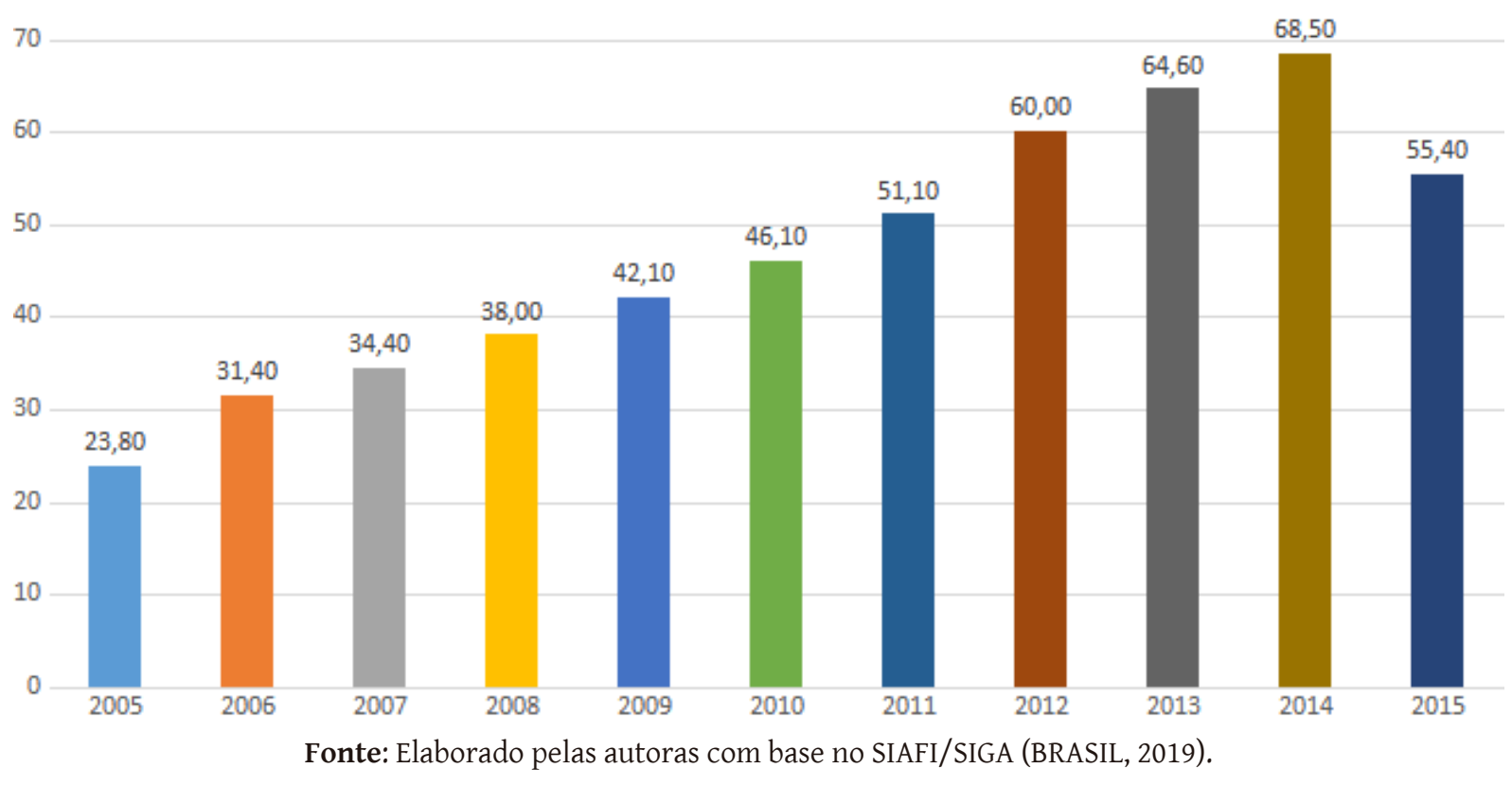

As transferências seguem uma curva crescente, chegando ao seu ápice em 2014, apresentando uma queda em 2015, resultante de uma crise econômica que o país começa a enfrentar, depois de anos de crescimento da economia, do trabalho formal, de programas de transferência de renda e de serviços socioassistenciais. O Censo SUAS 2017 explica que o começo desse crescimento acima da média, verificado em 2004, se comparado aos anos anteriores, é consequência de novas disposições legais instituídas em 2003. Em outubro, o Governo Federal editou a Medida Provisória $\mathrm{n}^{\circ}$ 132, convertida na Lei $\mathrm{n}^{\circ}$ 10.836, de 9 de janeiro de 2004, que criou o PBF (BRASIL, 2004a), a fim de atender às famílias em situação de pobreza e extrema pobreza. A partir desse momento, houve um rápido crescimento no número de famílias beneficiadas, que passou de 1,2 milhão, em 2003, para 6,6 milhões, em 2004; nos anos subsequentes, vem a implantação dos serviços, que também elevam as despesas e os investimentos. 
O Caderno SUAS, lançado em 2013, que trata do financiamento da assistência social, coloca que outro marco legal, que gerou impacto relevante nas despesas com as transferências de renda, foi a promulgação do Estatuto do Idoso - Lei nº 10.741, de $1^{\circ}$ de outubro de 2003 (BRASIL, 2003a) que, entre outras medidas, reduziu a idade de concessão do Benefício de Prestação Continuada para a Pessoa Idosa (BPC-Idoso), de 67 para 65 anos, e estabeleceu a não contabilização para efeito de apuração da renda familiar per capita do benefício já concedido a outro idoso da família. Destaca-se, também, nessa série histórica, a política de aumento real do salário-mínimo, adotada naqueles anos, o que produziu impacto direto no financiamento do BPC. Os programas de transferência de renda foram os principais responsáveis pelo salto quantitativo no orçamento da assistência social, que, desde seu surgimento, ocupam cerca de 90\%, com oscilações, dos gastos da assistência social, deixando evidente o lugar marginal dos serviços socioassistenciais nesse modelo de assistência social adotado, conforme ilustra o gráfico 2, a seguir.

Gráfico 2 - Valores repassados aos programas de transferência de renda - Brasil (2002-2015)

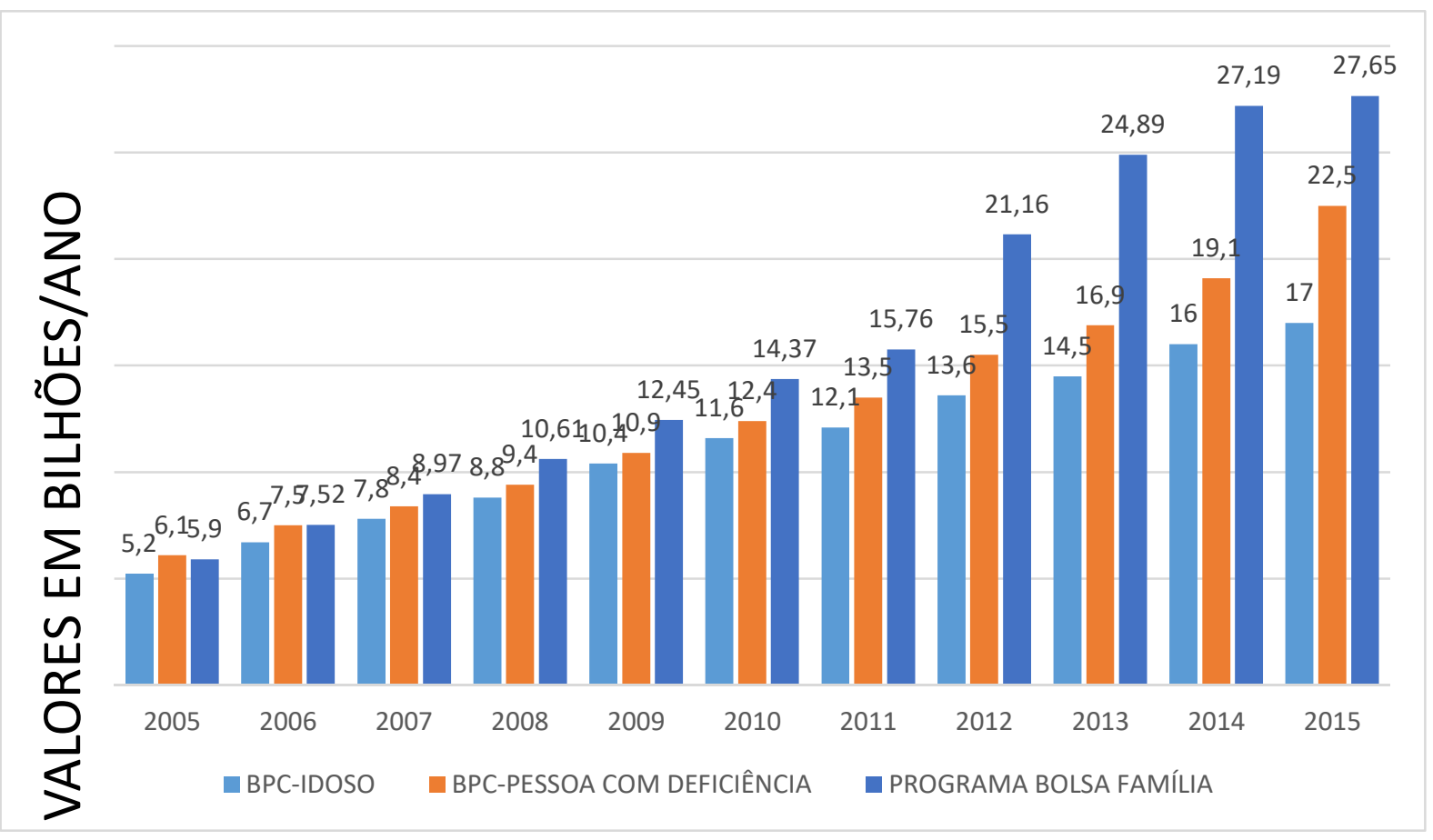

Fonte: Elaborado pelas autoras com base no SIAFI/SIGA (BRASIL, 2019).

Os dados indicam elevação, em valores constantes, de R $\$ 1,7$ bilhão, em 2002, para R $\$ 5,8$ bilhões, em 2012, equivalente a 246,2\% de aumento real. Tal incremento está relacionado também à expansão dos serviços socioassistenciais desenvolvidos nos CRAS e nos CREAS; à ampliação do Programa de Segurança Alimentar e Nutricional e, nos últimos exercícios, às ações de apoio à gestão do SUAS e do Bolsa Família.

Destarte, é importante fazer uma relação com o cenário político dos anos de implantação do SUAS, com o projeto governamental, suas prioridades e linhas de investimentos. Nesse período, o Brasil esteve sob o comando do presidente eleito, Luís Inácio Lula da Silva, do Partido dos Trabalhadores (PT), partido considerado de centro-esquerda, de caráter democrático-popular, que, embora tenha contribuído consideravelmente para a implantação do SUAS e do PAIF em todo o território nacional, não confrontou a proposta neoliberal do capitalismo, como era esperado. Entretanto, adotou uma versão mais flexível desse ideário, que foi denominada de 
neodesenvolvimentismo ${ }^{3}$. Esse modelo de desenvolvimento foi seguido nos dois mandatos consecutivos de Lula, e nos mandatos seguintes da presidenta Dilma Rousseff, também do Partido dos Trabalhadores.

A quantidade de famílias beneficiárias do Programa Bolsa Família cresceu 60,2\% entre os anos de 2005 e 2015, passando de 8.700.445 famílias, em 2005, para um total de 13.936.791 famílias beneficiárias do Programa, em 2015, crescimento que se deve à política daqueles Governos. Por outro lado, a baixa prioridade nos serviços socioassistenciais é marca do familismo no Brasil, pois, conforme Teixeira (2016), se prioriza a transferência de renda e espera-se que a família provenha os serviços de assistência, cuidados e proteção social. Nessa perspectiva, o PAIF, principal serviço dirigido às famílias, tem por objetivo potencializar essas funções protetivas da família, mantendo-as ativadas e sendo compreendidas como forma de fortalecer os vínculos familiares, pela via do aumento das responsabilidades familiares; assim, incluem-se expressões como protagonismo e autonomia.

Nessa direção, de acordo com Mota (2010), houve assistencialização da proteção social, porque a assistência social, mediante programas de transferência de renda, foi a principal forma de inclusão social, denominando de fetiche o que se deve à focalização no combate à pobreza nesses Governos de esquerda no Brasil, aderindo ao receituário neoliberal de que essa deve ser a priorização e o foco das políticas sociais públicas, deixando os que podem pagar buscarem no mercado os serviços, na contramão do reforço das políticas universalistas.

Apesar da centralidade nos programas de transferência de renda, a estrutura pública dos CRAS e CREAS foi criada, e cresceu em todo o território nacional. Houve a formação das equipes por contratação, ou via concursos públicos; a implementação dos serviços pelo poder público ou em parceria com a sociedade civil; e, no caso do PAIF, como exclusivo dos CRAS, ganhou uma ampla dimensão, chegando a todos os municípios brasileiros, dada a centralidade na família e no território de vulnerabilidades sociais, sendo os demais serviços complementares a eles.

Nesse cenário, muitos municípios se destacam, mas daremos ênfase ao município de Teresina, capital do estado do Piauí, um dos mais pobres do país, localizado na região Nordeste do país, município de moradia e de pesquisa das autoras. Mas também à situação do município, que cresce em oferta de serviços e na criação de unidades públicas de atendimento e acompanhamento das famílias, destacando-se como gestão plena. Os dados do município foram recortados com base nas informações oferecidas pelo RMA e disponibilizadas no site oficial do Ministério da Cidadania, sendo agrupados e expostos em gráficos e tabelas, observando sua curva de crescimento ou o retrocesso nas duas séries históricas.

\section{O serviço PAIF e o trabalho social com famílias nos CRAS de Teresina-PI}

Atualmente, a Secretaria Municipal de Cidadania, Assistência Social e Políticas Integradas (SEMCASPI) é o órgão da administração direta do poder executivo municipal responsável pelo planejamento, pela coordenação e execução da Política de Assistência Social, regulamentada pela Lei Federal nº 8.742/93 - LOAS - no município de Teresina, que hoje possui 19 CRAS e 4 CREAS,

\footnotetext{
${ }^{3}$ Modelo de desenvolvimento (econômico e social) que visou, de um lado, criar condições para o crescimento da economia capitalista e, por outro lado, ampliar o mercado de consumo interno, através da redução da pobreza e de políticas sociais focalizadas nos mais pobres, no qual o investimento na política de assistência social e nos programas de transferência de renda tornaram-se decisivos para amenizar as expressões da questão social, principalmente a fome e a miséria, conforme Alves (2020).
} 
distribuídos nas 4 zonas da cidade (leste, norte, sudeste e sul), denominadas de territórios, cuja abrangência envolve parques, bairros, vilas e residenciais.

O quadro 2, abaixo, demonstra o volume dos atendimentos realizados pelo PAIF nos 19 CRAS do município de Teresina, no período de 2012 a 2015, de acordo com dados fornecidos pelo RMA ${ }^{4}$.

Quadro 2 - Atendimentos realizados no serviço PAIF nos 19 CRAS de Teresina 2012 -2015

\begin{tabular}{|l|l|l|l|l|}
\hline \multirow{2}{*}{ ATENDIMENTOS REALIZADOS PELO CRAS/PAIF /ANO } & \multicolumn{4}{|c|}{ QUANTIDADE } \\
\cline { 2 - 6 } & $\mathbf{2 0 1 2}$ & $\mathbf{2 0 1 3}$ & $\mathbf{2 0 1 4}$ & $\mathbf{2 0 1 5}$ \\
\hline Total de famílias em acompanhamento pelo PAIF & 31.704 & 32.808 & 85.000 & 95.000 \\
\hline Total de famílias inseridas no acompanhamento do PAIF/ano & 3.199 & 2.507 & 1.377 & 2.548 \\
\hline Total de atendimentos individualizados realizados & 116.037 & 120.769 & 128.802 & 135.000 \\
\hline Total de Famílias participando regularmente de grupos no âmbito do PAIF & 8.703 & 4.566 & 7.401 & 8.728 \\
\hline Total de atendimentos coletivos do PAIF & 68.229 & 78.149 & 74.502 & 74.931 \\
\hline
\end{tabular}

Fonte: Elaborado pelas autoras com base no RMA (2012-2015).

Vale ressaltar que o trabalho com famílias do PAIF se materializa tanto em atendimentos a alguns membros da família e/ou em acompanhamentos, geralmente para as famílias que apresentam situação de maior vulnerabilidade e de um iminente risco, se algo não for feito para prevenir. Salta aos olhos o crescimento gradativo, ano a ano, do trabalho individualizado, chegando a 135.000 casos em 2015; enquanto o total de famílias em acompanhamento é de apenas 95.000 casos, as que participam regularmente dos grupos do PAIF são apenas 8.728 casos. Isso diz muito sobre o seu potencial preventivo e da focalização presente nele. Como destaca Teixeira (2016), essa individualização é a expressão dos CRAS como um serviço cartorial, um balcão de encaminhamentos para a rede, com pouca efetividade em oferecer soluções, a partir do serviço, para um número crescente de famílias.

Apesar disso, a realidade explicitada no quadro 2 demonstra que o total de familias em acompanhamentos realizados nos 19 CRAS se apresenta crescente, quando se verifica, em 2012, o volume anual de atendimento de 3.704, chegando, em 2015, aos 95.000, o que corresponde ao aumento de $156 \%$ nos períodos estudados. Geralmente, o acompanhamento realiza-se por meio da participação sistemática da família em atividades coletivas desenvolvidas no âmbito do PAIF, portanto, o que caracteriza o acompanhamento é, fundamentalmente, o contato sistemático e planejado com a família, orientado ao alcance de objetivos estabelecidos.

Mas, considerando os objetivos do serviço, de potencializar as funções protetivas da família e de fortalecer vínculos familiares, pressupõe-se parceria com a família - estabelecimento de compromissos, novas responsabilidades familiares - que não rompe, mas mantém e reproduz as expectativas sociais ancoradas nos papéis assimétricos de gênero; assim como preserva a visão idílica da família como fonte de proteção, cuidado, amor, assistência, sobrevivência, sem

${ }^{4}$ É regulamentado pela Resolução CIT nº 20, de 13 de dezembro de 2013, que institui parâmetros nacionais para o registro das informações relativas aos serviços ofertados nos Centros de Referência da Assistência Social (CRAS), nos Centros de Referência Especializados da Assistência Social (CREAS) e Centros de Referência Especializados para População em Situação de Rua - Centro Pop (BRASIL, 2013). 
contradições, ambiguidades e relações de força, e sem, contudo, oferecer condições materiais e socioeducativas que revertam os processos de vulnerabilidade social.

Esse modus operandi de realizar acompanhamento das famílias está subjacente à lógica de que os problemas vivenciados pelas famílias são vistos como falhas individuais e de incapacidade de elas protegerem seus membros, de realizarem as condicionalidades do Programa Bolsa Família. Assim, embora seja crescente o número de atendimentos, e também de acompanhamentos, de 2012 a 2015, em Teresina, acompanhando o crescimento do SUAS em todo o país e a ampliação de seu financiamento, a tendência visível é de atendimentos individualizados, baixa incidência de trabalhos coletivos, muitas vezes atribuídas à não adesão das famílias, e não aos procedimentos utilizados. O que se expressa na permanência de traços familistas, confirmando a tese de Teixeira (2010, p. 10), quando afirma que "[...] a Política de Assistência Social e o SUAS (2005), ainda não conseguiram superar a tendência familista da política social brasileira."

O familismo se caracteriza como uma tendência da política social de esperar, incentivar e fortalecer o papel da família na proteção social, o que amplia as responsabilidades familiares e gera sobrecarga, ao manter as expectativas de sua participação na provisão do bem-estar e da proteção dos seus membros. A intervenção do Estado só se fará presente na impossibilidade de a família proteger seus membros (TEIXEIRA, 2010; MIOTO, 2016). Como destaca Mioto (2016), o trabalho social com família acaba por se apresentar numa lógica em que essa é entendida como parte do problema, da dificuldade apresentada, e a solução estando centrada nela própria, na sua capacidade de superação, no capital humano que possui, no seu protagonismo, o que revela a contradição da inclusão da família na Política de Assistência Social, ora como agente de proteção social, ora como sujeito de direitos, que deve ser cuidada para poder cuidar, como destaca Teixeira (2018).

Considerando a política governamental, há prevalência dos programas de transferência de renda. 0 quadro 3, a seguir, demonstra a quantidade de famílias inseridas no Cadastro Único, e as famílias beneficiárias do Programa Bolsa Família.

Quadro 3 - Programa de renda mínima: gestão do cadastro único para programas sociais e Programa Bolsa Família, em Teresina, de 2013 a 2015

\begin{tabular}{|l|l|l|l|l|}
\hline \multirow{2}{*}{ DESCRIÇÃo } & \multicolumn{3}{l|}{ QUANTIDADE } \\
\cline { 2 - 6 } & $\mathbf{2 0 1 2}$ & $\mathbf{2 0 1 3}$ & $\mathbf{2 0 1 4}$ & $\mathbf{2 0 1 5}$ \\
\hline Famílias cadastradas no CadÚnico & 0 & 118.061 & 128.400 & 115.954 \\
\hline Família beneficiárias do PBF & 0 & 67.699 & 66.443 & 69.852 \\
\hline
\end{tabular}

Fonte: Elaborado pelas autoras com base no Relatório de Gestão da SEMTCAS (TERESINA, 2016).

O Programa Bolsa Família está inserido na Política de Assistência Social como um programa de transferência de renda direta, como estratégia de redução da pobreza e da desigualdade social (CUNHA, 2009). A entrada da família no PBF ocorre mediante cadastramento no CadÚnico, que é o Cadastramento Único do Governo Federal, direcionado às famílias em situação de pobreza e de extrema pobreza (BRASIL, 2007). Entretanto, o PBF beneficiou, no período pesquisado, apenas $60 \%$ dessas famílias cadastradas, persistindo um déficit para ser corrigido no combate à pobreza.

O crescimento do PAIF, seja em atendimentos ou em acompanhamentos, está diretamente relacionado ao crescimento da cobertura dos programas de transferência de renda até 2015. Como se pode observar nos dados estatísticos, os programas de transferência de renda ganharam ampla legitimidade, maior do que a dos serviços, pela força do tamanho da pobreza e do familismo da 
política, que visa reforçar as responsabilidades das famílias. Entretanto, a realidade dos CRAS de Teresina é perpassada pelo o que Mioto $(2004$, p. 3) chama de “[...] processos de intervenção com famílias que são pensados apenas no âmbito do atendimento direto [...]", centrados, portanto, numa perspectiva individualizante, pouco planejada, com baixa incidência de trabalho socioeducativo com família, pautado na lógica protetiva dos direitos de cidadania, em que o acesso se daria apenas pela condição de ter a necessidade e ser cidadão de uma nação.

\section{O SUAS e o PAIF a partir do Governo de Michel Temer (2016 a 2018)}

A partir de 2016, um novo Governo foi iniciado no Brasil, após destituição da presidenta eleita, Dilma Rousseff, por meio de um processo de impeachment que levou à ascensão de Michel Temer, o vice-presidente, do Partido do Movimento Democrático Brasileiro (PMDB), à presidência do país. Esse Governo lançou seu projeto no documento "A Travessia - uma ponte para o futuro", assumindo a lógica neoliberal ortodoxa e a necessidade de um ajuste fiscal do Estado brasileiro, sob o pretexto de combater a crise econômica. Essas medidas de ajuste fiscal, bem como o corte direto do orçamento da assistência social, puseram em xeque a sua consolidação e o aperfeiçoamento naquela conjuntura, no que se refere à continuidade do crescimento e das ações conquistadas nos últimos 10 anos no SUAS (GUTIERRES, 2017).

Entretanto, a mais significativa mudança para as políticas de seguridade social foi a Proposta de Emenda Constitucional (PEC) nº 241/2016, posteriormente denominada Emenda Constitucional no 95 (BRASIL, 2016b), que instituiu o Novo Regime Fiscal (NRF) para a União, durante os próximos 20 anos. Essa medida vem desestruturando o financiamento da política social, pois reduz as possibilidades de atuação do Estado na área social. A situação da assistência social não foi pior pela pressão das organizações sociais de defesa do SUAS, que questionaram os cortes de recursos lutaram, e lutam, pela retomada do crescimento.

Gráfico 3 - Recursos transferidos da União para o financiamento da assistência social - a partir do Governo Michel Temer - Brasil (2016-2018)

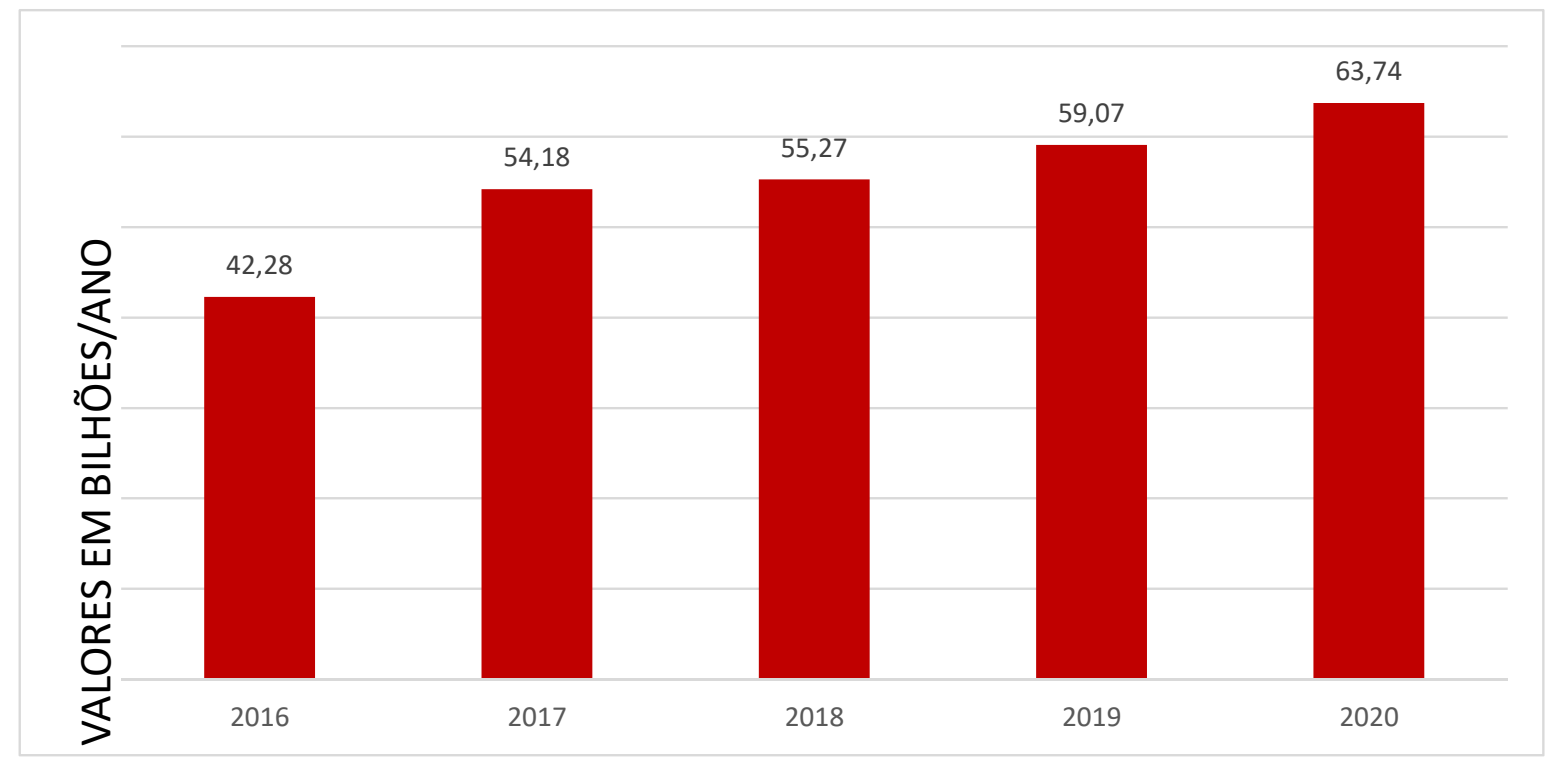

Fonte: Elaborado pelas pesquisadoras com base em SIAFI/SIGA (2019). 
Destaca-se que, já em 2015, o orçamento da assistência social sofreu drástica queda, saindo de 68,5 bilhões, em 2014, para 55,4 bilhões (ver quadro 1). Os dados do gráfico 4 revelam o orçamento de apenas 48,28 bilhões em 2016, portanto, mais um corte significativo no financiamento da política. Em 2017 e 2018, ele volta a crescer, chegando a 55,27 bilhões. Apesar do crescimento, não chegou às cifras que atingiu na "fase ouro" da assistência social no Brasil.

Salienta-se que a garantia de renda à população pauperizada teve papel proeminente no enfrentamento da pobreza e na promoção da cidadania inclusiva, o que faz do direcionamento dos recursos assistenciais uma escolha acertada (PASSOS; SANTOS; SCARPARI, 2019). Contudo, os programas de transferência de renda ainda continuaram absorvendo a maior parte do orçamento da assistência social, mas seu ritmo de crescimento foi lento, se comparado à série histórica anterior, como mostra o gráfico 4 , a seguir.

Gráfico 4 - Evolução de gastos com programas de transferência de renda - Brasil (2016-2019)

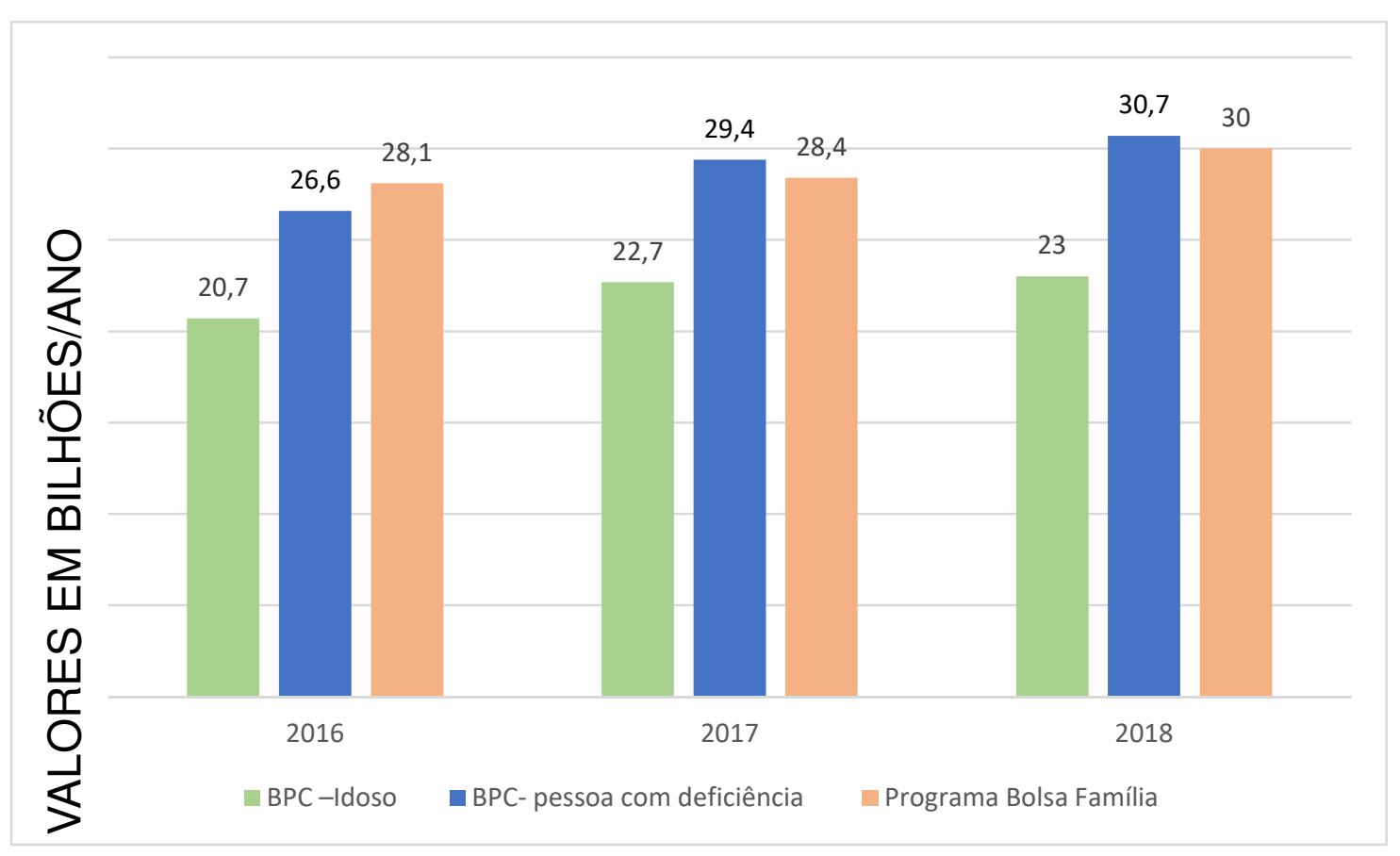

Fonte: SIAFI/SIGA (BRASIL, 2019).

De acordo com o gráfico 4, os benefícios de transferência de renda continuaram crescendo porque o país teve maior número de desempregados e de pobreza. Além disso, a política social neoliberal valoriza a transferência de renda aos mais pobres, com condicionalidade, especialmente, menos do que um salário mínimo; o que explica o permanente crescimento do PBF. Mas o ritmo do crescimento foi desigual entre eles, o menor crescimento foi no BPC Idoso, que quase estagnou. O PBF teve crescimento leve em 2018, o que se deve ao período eleitoral, e, em 2019, logo que teve início o atual Governo, de Jair Bolsonaro.

De acordo com o caderno de Resultados 2018, publicado para divulgar as ações do Governo Michel Temer, a quantidade de famílias beneficiárias do Programa Bolsa Família, em 2018, chegou a 13,8 milhões, fato atribuído aos 4,8 milhões de pessoas que ingressaram no PBF em 2017, em decorrência da fila de espera Em 2016, esses programas consumiram 96,68\% dos recursos orçados para a consolidação do SUAS, que nesse item gasta $63,15 \%$ do orçamento (a maioria esmagadora com o BPC deficiência e BPC idoso), conforme dados do Portal da Transparência (BRASIL, 2016c). 
Como marca do governo de austeridade fiscal, além da aprovação do Novo Regime Fiscal, EC nº 95, o presidente Michel Temer lançou o Programa Criança Feliz ${ }^{5}$, na assistência social, configurando um retrocesso, pelo fato de apresentar cunho fiscalizador, higienista e familista, mas compatível com a perspectiva neoliberal de programas de orientações e práticas que visam responsabilizar as famílias, vigiar o cuidado que oferecem, sob a pretensão de estarem colaborando para melhoria desse cuidado.

Diante do contexto de retrocessos relacionados às necessidades de aprimoramento e ampliação dos serviços socioassistenciais já tipificados, cria-se um Programa "novo", e põe-se em risco a consolidação da Política de Assistência Social. O congelamento dos gastos sociais legitimados politicamente vem acirrando as expressões da questão social e da pobreza, ampliando as demandas pelo PAIF. Diante do exposto, indaga-se: o que nos revelam os dados sobre o PAIF no início dessa nova série histórica? O que o exemplo do município de Teresina-PI mostra?

\section{0 trabalho social com famílias no PAIF no território teresinense de 2016 a 2018}

Os reflexos desse novo cenário, que teve início em 2016, em um município de gestão plena, num estado com elevado nível de pobreza, especialmente no principal serviço da proteção social básica, pode ser vistos no quadro 4, a seguir, que congrega dados dos três primeiros anos do segundo momento do SUAS na série histórica, no âmbito do município de Teresina, com olhar atento às possíveis tendências do trabalho social com família.

Quadro 4 - Atendimentos e acompanhamentos PAIF nos 19 CRAS de Teresina 2016-2018

\begin{tabular}{|l|l|l|l|}
\hline \multirow{2}{*}{ ATENDIMENTO E ACOMPANHAMENTO DA FAMILIA PELO CRAS /ANO } & \multicolumn{3}{l|}{ QUANTIDADE } \\
\cline { 2 - 4 } & $\mathbf{2 0 1 6}$ & $\mathbf{2 0 1 7}$ & $\mathbf{2 0 1 8}$ \\
\hline Número de famílias acompanhadas & 31.704 & 32.808 & 85.000 \\
\hline Número de famílias inseridas para acompanhamento em cada ano & 922 & 869 & 1.1914 \\
\hline Total de atendimentos individualizados realizados & 140.535 & 219.036 & 288.847 \\
\hline Famílias participando regularmente de grupos no âmbito do PAIF & 12.919 & 4.766 & 7.568 \\
\hline Número de atendimentos coletivos & 97.447 & 64.316 & 89.534 \\
\hline
\end{tabular}

Fonte: Elaborado pelas autoras com base no RMA 2017-2018.

De acordo com os dados do RMA, a partir de 2015, último ano da primeira série histórica, em comparação aos anos dessa segunda série histórica (2016-2018), o número de famílias acompanhadas em 2018 chegou a 85.000, uma redução, quando comparamos com os números de 2015, que contou com $\mathbf{9 5 . 0 0 0}$ famílias acompanhadas. Os anos de 2016 e 2017 apresentaram números ainda menores, que refletem a precarização do serviço, de sua capacidade de acompanhamento das famílias pelas restrições orçamentárias, pelo ritmo menor do crescimento dos programas de transferência de renda, na contratação das equipes, entre outros. O ano de 2018 é exceção, em função de ser ano eleitoral e de fim de mandato.

\footnotetext{
${ }^{5}$ Definido pelo Conselho Nacional de Assistência Social como Primeira Infância no SUAS (Resolução nº 20, de 24 de novembro de 2016), tem como público-alvo crianças de 0 a 6 anos, e mulheres gestantes, vinculadas ao CRAS. O Programa consiste em uma equipe de visitadores, que realizam visitas semanais e quinzenais às famílias atendidas pelo Programa, para incentivar a ludicidade e orientar as famílias como cuidar dos seus filhos menores de 6 anos, como acessar a rede das políticas sociais, entre outros cuidados (BRASIL, 2016a).
} 
O número de famílias inseridas para acompanhamento por ano-base mostra que em $2016 \mathrm{e}$ 2017 teve-se o menor número de famílias inseridas em acompanhamento, chegando a 2018 com apenas 1.914. Esses foram anos difíceis, de crises, aumento do desemprego, precarização do trabalho, quando se esperaria mais famílias procurando o serviço, que pode ser observado pelo número crescente de atendimentos individualizados. Entretanto, eles não resultaram em acompanhamentos por falta de estrutura do serviço, de capacidade de fazer acompanhamentos sistematizados, levando a assistência social para atendimentos individualizantes, emergenciais, pontuais.

$O$ total de atendimentos individualizados realizados se expandiu ainda mais na segunda série, que se iniciou em 2016, chegando em 2018 com 288.487 atendimentos individualizados, um recorde de procura/demanda pelo serviço, o que só reforça seu caráter focalizado, de encaminhamentos e sem atividades de inclusão, via o próprio serviço do PAIF, mediante acompanhamentos particularizados ou grupais.

Numa contramarcha de execução dos serviços estão os dados no que se referem à quantidade de famílias participando regularmente de grupos no âmbito do PAIF, que, até 2016, se manteve em crescimento, somando 12.919 famílias participando de grupos. Em 2017, sofreu decréscimo para 4.766 famílias em acompanhamento regular, chegando, em 2018, com 7.568, o que representa apenas 30\% dos acompanhamentos regulares em 2016.

A redução dos atendimentos e acompanhamentos coletivos, dentre os quais estão incluídos palestras, oficinas, grupos sobre diversas temáticas, vem se mostrando crescente ao longo das duas séries históricas analisadas, chegando, em 2018, a 89.534 atendimentos coletivos. Observa-se que os atendimentos coletivos não superam os individualizantes, e que essa modalidade coletiva está para além da quantidade de famílias em acompanhamento, o que se deve à adoção dessa modalidade como capaz de atender a um público maior, de ser capaz de sensibilizar as familias para a necessidade de acompanhamentos. Entretanto, destoa da quantidade de pessoas que são de fato acompanhadas, e da quantidade que se insere, anualmente, para o acompanhamento.

Esses dados levam a perceber o reforço do familismo e as expectativas de que as famílias se responsabilizem por prestar os serviços de assistência aos seus membros, no seu lar, sendo os acompanhamentos exclusivos para as que "falirem" nessas funções protetivas. Assim, vê-se um serviço preventivo da assistência social se transformar em serviços para situações-limites, um crivo de seletividade crescente e distanciamento da universidade no grupo dos que necessitam, tendências predominantes com o avanço da lógica neoliberal ortodoxa.

As informações sobre as famílias beneficiadas pelo Programa Bolsa Família no município e as incluídas no CadÚnico são importantes para traçar as tendências do trabalho social com famílias, pois, os primeiros são alvo do PAIF, público prioritário, e o segundo mostra a demanda reprimida pelo benefício.

Quadro 5 - Programas de renda mínima: gestão do Cadastro Único para programas sociais e Programa Bolsa Família Teresina de 2016-2018*

\begin{tabular}{|l|l|l|l|}
\hline \multirow{2}{*}{ DESCRIÇÃO } & \multicolumn{3}{l|}{ QUANTIDADE } \\
\cline { 2 - 4 } & $\mathbf{2 0 1 6}$ & $\mathbf{2 0 1 7}$ & $\mathbf{2 0 1 8}$ \\
\hline Famílias cadastradas no CadÚnico & 112.546 & 97.749 & 101.683 \\
\hline Família beneficiarias do PBF & 64.210 & 51.436 & 58.475 \\
\hline
\end{tabular}

Fonte: Elaborado pelas pesquisadoras, com base no Relatório de Gestão da SEMTCAS (TERESINA, 2016).

*Os dados referentes 2017, 2018 são fornecidos pelo Relatório de gestão da SEMCASPI (TERESINA, 2018). 
Os dados nos revelam uma queda tanto no número de famílias cadastradas como no número de famílias beneficiadas pelo Programa Bolsa Família. A distorção se amplia entre famílias cadastradas na condição de baixa renda e as que têm acesso, uma diferença de $42 \%$, quando, em 2015, era de apenas 30\% de famílias fora do Programa. Essas famílias incluídas, especialmente as em descumprimento de condicionalidades, constituem público prioritário para inserção em acompanhamento nas atividades do serviço PAIF, por meio do trabalho social com famílias. A redução da cobertura influencia os dados sobre o acompanhamento, que teve redução nessa série histórica, principalmente porque permanecer no PBF mobiliza as famílias para aceitarem o acompanhamento. Esse cenário é expressão dos cortes no Programa, do acirramento nos critérios ultrasseletivos para inserção, das precariedades das condições de acompanhamento, entre outros.

\section{Conclusão}

Os dados empíricos analisados nos revelam que o trabalho social com família, tanto no contexto nacional como no âmbito do município de Teresina, apresenta como tendências: atendimentos individualizados predominantes diante do acompanhamento, com o PAIF com dimensões cartoriais/balcão de atendimentos; reforço do familismo pela predominância dos benefícios; baixa inclusão e acompanhamento das famílias no PAIF; e, quando da sua inclusão, há o reforço da lógica protetiva da própria família nos enfrentamentos das vulnerabilidades, postos pelos objetivos do serviço; reforço da assistencialização pela via das transferências de renda, mais restritivo aos em extrema pobreza; invisibilidade do PAIF, pela predominância de atendimentos em detrimento dos acompanhamentos; prevalência de ações imediatistas, emergenciais e não planejadas; acompanhamentos seletivos predominantes sobre as famílias que "faliram" nas funções protetivas. Essas tendências, parcialmente postas na primeira série histórica, avolumaram-se e se consolidaram na segunda série, que se iniciou em 2016, em decorrência do congelamento e de cortes orçamentários, que não chegaram ao patamar de 2014, momento de maior expressão do aumento do financiamento da política.

As análises nos permitem concluir que o TSF do PAIF se apresenta de modo contraditório, uma vez que, no modus operandi, ainda há baixa incidência de acompanhamentos, e do uso de trabalho coletivo, focalizado nas famílias que "fracassaram" e na expectativa de que elas devem cumprir seu papel como responsáveis pelo desenvolvimento de seus membros, para poderem merecer atenção. Na comparação dos dois períodos, percebe-se a forte assistencialização da proteção social, em que a assistência social seguirá sendo a principal forma de acesso à proteção social, ainda que cada vez mais restrita aos mais vulneráveis, que conduz à redução dos direitos sociais ou de políticas garantidoras, pela via da universalidade, ampliando a noção de política social focalizada e compensatória.

O desvendamento dessas tendências só foi possível porque os dados, como singularidades ou totalidades parciais, foram inseridos mediante mediações determinantes, como as categorias do familismo; da proteção social inclusiva e universal, ainda que fundamentada na equidade; na intervenção social de cidadania e a de balcão/cartorial que empurra problemas para frente, sem contrarreferências, fluxos e protocolo oficiais, legais e contínuos, e a relação com a sociedade brasileira de cada momento histórico das duas séries históricas, dos governos e suas plataformas, dentre outras, sempre do singular para o geral e vice-versa. 


\section{Referências}

ALVES, G. Neodesenvolvimentismo e precarização do trabalho no Brasil - Parte II. Disponível em: https://blogdaboitempo.com.br/. Acesso em: 28 abr. 2020.

BRAGA, I. A. Trabalho social com família: requisições profissionais e especificidades metodológicas no SUAS. In: BRAGA, I. A. (Org.). O Sistema Único da Assistência social no contexto piauiense: contribuições ao debate. Teresina: EdUFPI, 2018. p. 151-172.

BRASIL. Constituição Federal Brasileira. Distrito Federal: Senado Federal, 1988.

BRASIL. Decreto $\mathbf{n}^{\mathbf{0}} \mathbf{6 . 1 3 5}$, de 26 de junho de 2007. Dispõe sobre o Cadastro Único para os programas sociais do Governo Federal e dá outras providências. Disponível em: http://www.planalto.gov.br/ ccivil_03/_ato2007-2010/2007/decreto/d6135.htm Acesso em: 10 abr. 2020.

BRASIL. Decreto no 8.869, de 5 de outubro de 2016a, institui o Programa Criança Feliz. Disponível em: https://www.in.gov.br/materia/-/asset_publisher/Kujrw0TZC2Mb/content/id/21292775/do1-201610-06-decreto-n-8-869-de-5-de-outubro-de-2016-21292718. Acesso em: 20 abr. 2020.

BRASIL. Emenda constitucional no 95, de 15 de dezembro de 2016b. Dispõe sobre o novo Regime Fiscal. Disponível em: http://www.planalto.gov.br/ccivil_03/constituicao/emendas/emc/emc95.htm Acesso em: 9 out. 2019.

BRASIL. Fundo Nacional de Assistência Social - FNAS. 2016c. Portal da Transparência. Disponível em: http://www.portaltransparencia.gov.br/funcoes/08-assistencia-social?ano=2019. Acesso em: 3 mai. 2020.

BRASIL. Lei $\mathbf{n}^{\mathbf{0}} \mathbf{1 0 . 7 4 1}$, de 1ํㅡㄹ de outubro de 2003a. Dispõe sobre o Estatuto do Idoso e dá outras providências. Disponível em: http://www.planalto.gov.br/ccivil_03/leis/2003/l10.741.htm. Acesso em: $10 \mathrm{abr} .2020$.

BRASIL. Lei no 10.836, de 9 de janeiro de 2004a, cria o Programa Bolsa Família e dá outras providências. Disponível em: https://www2.camara.leg.br/legin/fed/lei/2004/lei-10836-9-janeiro-2004-490604publicacaooriginal-1-pl.html/. Acesso em: 08 jun. 2020.

BRASIL. Lei no 12.435, de 6 de julho de 2011. Dispõe sobre a Organização da Assistência Social (LOAS). Disponível em: https://legislacao.presidencia.gov.br/ atos/?tipo=LEI\&numero=12435\&ano=2011\&ato=d5cITVE1UMVpWT52b . Acesso em: 30 set. 2019.

BRASIL. Medida Provisória no 132, de 20 de outubro de 2003b, cria o Programa Bolsa Família e dá outras providências. Disponível em: https://www.congressonacional.leg.br/materias/medidasprovisorias/-/mpv/63208. Acesso em: 15 abr. 2020.

BRASIL. Ministério de Desenvolvimento Social e Combate à Fome (MDS). Orientações Técnicas sobre o PAIF: o Serviço de Proteção e Atendimento Integral a Família - PAIF segundo a Tipificação Nacional dos Serviços Socioassistenciais. v. 1, 1. ed. Brasília: MDS, 2012a.

BRASIL. Ministério de Desenvolvimento Social e Combate à Fome. Norma Operacional Básica da Assistência Social (NOB/SUAS). Brasília: MDS\SNAS, 2005.

BRASIL. Ministério de Desenvolvimento Social e Combate à Fome. Orientações Técnicas sobre o PAIF: Trabalho Social com Famílias do Serviço de Proteção e Atendimento Integral a Família - PAIF. v. 2, 1. ed. Brasília: MDS, 2012b.

BRASIL. Ministério do Desenvolvimento Social e Combate à Fome. Política Nacional de Assistência Social (PNAS). Brasília: MDS/SNAS, $2004 b$. 
BRASIL. Ministério do Desenvolvimento Social e Combate à Fome. Portaria no $\mathbf{8 0}$, de 02 de abril de 2004c. Estabelece os critérios e procedimentos relativos à transferência de recursos financeiros para os Fundos Estaduais, do Distrito Federal e Municipais, destinados à rede de Serviços Assistenciais de Ação Continuada. Disponível em: http://blog.mds.gov.br/redesuas/portaria-no-80-de-2-de-abril-de-2004/. Acesso em: 10 mai. 2020.

BRASIL. Ministério do Desenvolvimento Social e Combate à Fome. Resolução CIT no 7, de 10 de setembro de 2009. Protocolo de Gestão Integrada de Serviços, Benefícios e Transferências de Renda no âmbito do SUAS. Brasília: MDS \CNAS, 2009b.

BRASIL. Ministério do Desenvolvimento Social e Combate à fome. Resolução CIT no 20, de 13 de dezembro de 2013. Relatório Mensal de Atendimento - RMA CRAS. Brasília: MDS \CNAS, 2013a.

BRASIL. O financiamento da assistência social. Caderno SUAS, ano 6, n. 6, Brasília: Ministério do Desenvolvimento Social e Combate à Fome, Secretaria Nacional de Assistência Social, 2013b.

BRASIL. Resolução CNAS no 269, de 13 de dezembro de 2006. Aprova a Norma Operacional Básica de Recursos Humanos do Sistema Único de Assistência Social - NOB-RH/SUAS. Disponível em: http:// www.mds.gov.br/webarquivos/legislacao/assistencia_social/resolucoes/2006/Resolucao\%20CNAS\%20 no\%20269-\%20de\%2013\%20de\%20dezembro\%20de\%202006.pdf/. Acesso em: 8 set. 2020.

BRASIL. Resolução no 109, de 11 de novembro de 2009. Aprova a Tipificação Nacional de Serviços Socioassistenciais. Diário Oficial da União, Brasília, DF, 25 nov. 2009a.

BRASIL. Resolução no 33, de 12 de dezembro de 2012c. Aprova a Norma Operacional Básica do Sistema Único de Assistência Social (NOB/SUAS). Disponível em: http://blog.mds.gov.br/redesuas/resolucaono-33-de-12-de-dezembro-de-2012/. Acesso em: 20 set. 2019.

BRASIL. Siga Brasil Portal do Orçamento do Senado Federal. Orçamento Federal de 2019. Disponível em: https://www12.senado.leg.br/orcamento/sigabrasil. Acesso em: 15 jun. 2020.

CUNHA, R. Transferência de renda com condicionalidade: a experiência do Programa Bolsa Família. In: BRASIL. Ministério de Desenvolvimento Social e Combate à Fome - MDS. Concepção e gestão da proteção social não contributiva no Brasil. Brasília, UNESCO, 2009. p. 331-362.

FIUZA, S. C. R.; COSTA, L. C. O direito à assistência social: o desafio de superar as práticas clientelista. Serviço Social em Revista, Londrina, v. 17, n. 2, p. 64 -90, jan./jun. 2015. Disponível em: http://www. uel.br/revistas/uel/index.php/ssrevista/article/view/19220. Acesso em: 28 jun. 2020.

GUTIERRES, K. A. Trajetória da assistência social como direito e o futuro incerto do sistema único da assistência social, Revista Perseu, São Paulo, Ano 11, n. 13, 2017. p. 86-107. Disponível em: https:// revistaperseu.fpabramo.org.br/index.php/revista-perseu/article/view/124. Acesso em: 2 abr. 2020.

IAMAMOTO, M. V. A herança conservadora do serviço social: atualização e busca de ruptura. In: IAMAMOTO. M. V. Renovação e conservadorismo no serviço social: Ensaios críticos. São Paulo: Cortez, 2013. p. 19-44.

MIOTO, R. C. T. Ações socioeducativas em Programas de transferência de renda. In: WANDERLEY, M. B.; OLIVEIRA, I. C. (Org.). Trabalho com famílias: textos de apoio, v. 2. São Paulo: IEF/PUC-SP, 2004. p. $45-51$.

MIOTO, R. C. T. O trabalho social com famílias: entre as amarras do passado e os dilemas do presente. In: TEIXEIRA, M. S. (Org.). Política de assistência social e temas correlatos. Campinas, SP: Papel Social, 2016. p. 215-232. 
MOTA, A. E. A. A centralidade da assistência social na seguridade brasileira nos anos 2000. In: MOTA, A. E. (Org.). O mito da assistência social. São Paulo: Cortez, 2010. p. 133-146.

PASSOS, L; SANTOS A. A.; SCARPARI. A. Financiamento da Política de Assistência Social: avanços e perspectivas. Textos \& Contextos, Porto Alegre, v. 18, n. 1, p. 91-109, jan./jun. 2019. Disponível em: https://revistaseletronicas.pucrs.br/ojs/index.php/fass/article/view/33523. Acesso em: 25 mai. 2020.

TERESINA. SEMTCAS. Relatório de Gestão 2013-2016. Teresina, 2016.

TERESINA. SEMCASPI. Relatório de Gestão 2017-2018. Teresina, 2018.

TEIXEIRA, S. M. Trabalho Social com Famílias na Política de Assistência Social: elementos para sua reconstrução em bases críticas. Serviço Social em Revista, Londrina, v. 13, n. 1, p. 4-23, jul./dez. 2010.

TEIXEIRA, S. M. A família na política de assistência social: concepções e as tendências do trabalho social com famílias nos CRAS de Teresina. 2. ed. Teresina: EdUFPI, 2016.

TEIXEIRA, S. M. Trabalho social com família: fundamentos históricos, teórico-metodológicos e técnico-operativos. Teresina: EdUFPI, 2018. 